\title{
Risk factors for trisomy 21: Maternal cigarette smoking and oral contraceptive use in a population-based case-control study
}

\author{
Quanhe Yang, PhD, Stephanie L. Sherman, PhD, Terry J. Hassold, PhD, Katherine Allran, MA, Lisa Taft, BA,
} Dorothy Pettay, BS, Muin J. Khoury, MD, PhD, J. David Erickson, DDS, PhD, and Sallie B. Freeman, PhD

\begin{abstract}
Purpose: We examined maternal smoking and oral contraceptive use as possible risk factors in the genesis of cases of trisomy 21 of maternal origin. This is the first epidemiological study to categorize cases of trisomy 21 by parent of origin and timing of the meiotic error before assessing possible risk factors. Methods: We used chromosome 21-specific DNA markers to assign origin to each case. Structured interviews were employed to determine maternal smoking and oral contraceptive use around conception. Results: The odds ratio (OR) for maternal smoking was significantly increased among younger mothers $(O R=2.98 ; 95 \% \mathrm{Cl}=1.01-8.87$ ), but only in a particular subset of meiotically-derived cases. The combined use of cigarettes and oral contraceptives increased the risk further ( $\mathrm{OR}=7.62 ; 95 \% \mathrm{Cl}=1.63-35.6)$; however, oral contraceptive use alone was not a significant risk factor. Conclusion: Our results indicate that categorizing cases of trisomy 21 by parent and timing of the meiotic error allows more precision in identifying risk factors and may shed light on mechanisms of meiotic nondisjunction. Genetics in Medicine, 1999:1(3):80-88.
\end{abstract}

Key words: cigarette smoking, oral contraceptives, Down syndrome, case-control study, trisomy 21, nondisjunction

\section{INTRODUCTION}

Down syndrome, the most common identified cause of mental retardation, occurs in approximately 1 in 800 live births. ${ }^{1}$ Ninety-five percent of the cases are the result of an extra, freestanding chromosome 21 (trisomy 21) which results from an error in meiosis (meiotic nondisjunction) or rarely, from an error in postzygotic mitosis. Throughout this article, the abbreviation DS will be used to refer exclusively to cases of trisomy 21 that are due to meiotic nondisjunction.

Despite many years of research to identify risk factors associated with DS, only one factor has been well established, advanced maternal age. The search for specific environmental risk factors has yielded few definitive results. ${ }^{2,3}$ The effect of smoking has been examined, and, interestingly, several studies have reported a nonsignificant negative association between maternal smoking around the time of conception and the risk for DS. ${ }^{4-8}$ Several investigators have suggested that this may be the result of selective prenatal loss of trisomic conceptuses among women who smoke. ${ }^{5,6}$ However, others have concluded that there is no association between DS and periconceptional smoking. ${ }^{9-12}$

It is important to note that previous studies on the effects of maternal smoking and other factors on the risk for DS have

\footnotetext{
From the Division of Birth Defects and Developmental Disabilities and the Office of Genetics and Disease Prevention, National Center for Environmental Health, Centers for Disease Control and Prevention (CDC); the Department of Genetics, Emory University School of Medicine, Atlanta, Georgia; the Department of Genetics and the Center for Human Genetics, Case Western Reserve University, Cleveland, Ohio; and the Office of Genetics and Disease Prevention, CDC, Atlanta, Georgia

Address correspondence to: Quanhe Yang, PhD, Birth Defects and Genetic Disease Branch BDDD, NCEH, 4770 Buford Hwy, MS F-45, Atlanta, GA 30341.E-mail: qay0@cdc.gov
}

pooled all trisomic individuals together regardless of the parent of origin or the timing of the chromosome error. With the advent of DNA technology and the generation of chromosome 21-specific genetic markers, it has become possible to determine both the parent in which the chromosome error occurred (maternal or paternal error) and the timing of that error during meiosis (meiosis I or II [MI or MII]). ${ }^{13-15}$ Thus, cases of trisomy 21 can be the result of an error in paternal meiosis I (PMI), paternal meiosis II (PMII), maternal meiosis I (MMI), or maternal meiosis II (MMII).

This is the first study to categorize DS cases by the parent of origin and the timing of the chromosome error to increase the power to identify important environmental or maternal healthrelated risk factors. However, recent molecular findings among maternally derived trisomy 21 cases have changed our thoughts about the timing of so-called MMII errors. ${ }^{16,17}$ These studies indicate that most cases of maternal nondisjunction, including the majority of those we classify as MMII, are initiated during MMI. This evidence is based on two observations. First, advanced maternal age is associated with both MMI and MMII errors. We expected the maternal age association for MMI errors because the arrest of MMI is initiated prenatally and continues until the egg is ovulated some 10 to 40 years later. However, the length of MMII is only 1 to 3 days, irrespective of the mother's age. Thus, the observed association between maternal age and MMII errors suggests that these errors may be initiated during MMI. Second, recombination, a meiosis I process known to be essential for proper chromosome segregation, is altered in cases involving both MMI and MMII errors. A lack of recombination or recombination that only occurs distally on chromosome 21 is associated with an MMI error, whereas recombination that occurs near the centromere 
increases the chance of an MMII error. These altered patterns of recombination are observed among both younger and older women and therefore do not seem to be related to maternal age. These results have led us to propose a two-hit hypothesis to explain the nondisjunction of chromosome $21 .{ }^{17}$ We suggest that the first hit occurs prenatally and involves the random establishment of a susceptible recombination pattern. The second hit is a maternal age-related disturbance of the meiotic process. The specific nature of this disturbance is not known, but it could include degradation of components of the meiotic process as the result of time and/or environmental exposures such as those investigated here. Susceptible meiotic components might include the spindle apparatus, chromatid adhesion proteins, or recombination-associated structures such as chiasmata.

These new data regarding the timing of maternally derived errors have prompted us to modify the terminology we use to refer to these errors. Nondisjunction is clearly of meiosis I origin if the pericentromeric markers that are heterozygous in the parent of origin of the two chromosomes 21 remain heterozygous in the child with DS. Therefore, we continue to refer to these as MMI errors. The problem arises in designating the errors which traditionally have been referred to as MMII. Classically, these have been identified as such because the pericentromeric markers, heterozygous in the parent of origin, are homozygous in the trisomic offspring, indicating failure of sister chromatid separation, a meiosis II process. These cases are clearly different from those designated as MMI because the pattern of recombination (increased and centromeric) is not the same as that seen in MMI cases (absent or decreased and distal). This characteristic recombination pattern, together with the advanced maternal age associated with these cases, has led us to suggest that most so-called MMII nondisjunction actually originates during meiosis I and continues through meiosis II, although there may be a small proportion of cases due to true MII nondisjunction. To emphasize this change of thinking without introducing unnecessary new terminology, we will use the designation "MMII" instead of MMII in this article.

Using a population-based case-control approach, we examined the effects of maternal cigarette smoking on nondisjunction resulting from either an MMI or an "MMII" error. In addition, because of the well-established risk for other health conditions related to the combination of smoking and oral contraceptive $(\mathrm{OC})$ use, we examined the effect of this interaction on the risk for a maternal meiotic error in chromosome segregation. ${ }^{18,19}$ No previous studies have reported on this interaction effect. We found a significant positive association between maternal smoking and DS in "MMII" cases and this effect was restricted to women younger than 35 years of age. In addition, we found a significantly increased odds ratio (OR) for smoking in combination with $\mathrm{OC}$ use around the time of conception in "MMII" cases of women younger than 35 years of age.

\section{SUBJECTS AND METHODS}

\section{Study population}

This work is part of an ongoing population-based casecontrol study of trisomy 21 in the five-county area of metropolitan Atlanta, Georgia. From 1989 through 1996, 358 liveborn infants with trisomy 21 were ascertained with the assistance of the Metropolitan Atlanta Congenital Defects Program (MACDP) of the Centers for Disease Control and Prevention (CDC). Details of this birth defect surveillance system are described elsewhere. ${ }^{20}$ The study was approved by the Human Investigations Committee of Emory University and informed consents were obtained from participants. Of 358 liveborn infants with DS, 249 were enrolled in the study (participation rate, $70 \%$ ). In addition, 114 pregnancy terminations were identified from one of the reference laboratories in the Atlanta area. These prenatally diagnosed cases were referred from throughout the five-county area and should be representative of all women having pregnancy terminations for DS, although it is not possible to document this definitively. Thirty-six of these 114 women (32\%) agreed to participate in the study. In addition, the MACDP randomly selected 524 unaffected, liveborn control infants from the same metropolitan Atlanta population. These infants were selected in proportion to the expected number of total births at each hospital. The parents of 329 of these control infants enrolled in the study (63\% participation rate). Table 1 summarizes the participation rates among cases and controls.

\section{Laboratory Methods}

For all liveborns with DS, blood samples were obtained from the parent(s) and child. For pregnancy terminations, we obtained tissue from the conceptus and blood from the parents. Using blood or tissue samples from case infants and their parents, we analyzed a battery of 45 chromosome 21 -specific DNA markers by Southern blotting or polymerase chain reaction (PCR) techniques. ${ }^{16}$ Parental origin of the extra chromosome was determined by examining the contribution of chromosome 21 alleles from each parent to his or her offspring. Information from at least two markers was required to assign the parental origin. The timing of the error was determined by comparing chromosome 21 pericentromeric markers of the parent who contributed the extra chromosome with those of the offspring (D21S369,

Table 1

Participation of case and control subjects, Atlanta, Georgia, 1989-1996

\begin{tabular}{|c|c|c|c|c|}
\hline \multirow[b]{2}{*}{ Disposition } & \multicolumn{3}{|c|}{ DS Cases } & \multirow[b]{2}{*}{ Controls } \\
\hline & Liveborn $^{a}$ & $\begin{array}{l}\text { Pregnancy } \\
\text { terminations }\end{array}$ & Total & \\
\hline Participated & 249 & 36 & 285 & 329 \\
\hline Refused & 47 & 33 & 80 & 77 \\
\hline Proband died & 19 & - & 19 & 0 \\
\hline Proband adopted & 7 & - & 7 & 0 \\
\hline Lost to follow-up & 9 & 40 & 49 & 61 \\
\hline In progress ${ }^{b}$ & 27 & 5 & 32 & 57 \\
\hline Total in 5-county area & 358 & $114^{c}$ & 472 & 524 \\
\hline Participation rate & $70 \%$ & $32 \%$ & $60 \%$ & $63 \%$ \\
\hline
\end{tabular}

"Seven mosaic DS cases were excluded from this total.

${ }^{b}$ Includes cases and controls currently being tracked as well as cases in which genotyping studies are in progress.

'Represents only a portion of total pregnancies terminated for trisomy 21 in the 5-county area. The total number is unknown. 
D21S215, D21S120, D21S258, D21S13, D21S16, D21S192). If parental heterozygosity was retained in the trisomic offspring, we concluded that an MI error had occurred. If parental heterozygosity was reduced to homozygosity, we designated the error as "MII." We distinguished a mitotic error from an "MII" error by evaluating other nonpericentromeric loci. Those cases with markers that were reduced to homozygosity along the entire chromosome were considered to be due to mitotic errors, and the remainder were designated "MII." The 12 cases caused by mitotic errors were excluded from this study. Further details about DNA analysis, parental origin, and meiotic stage classification have been described elsewhere. ${ }^{15}$

\section{Exposure status}

A standard questionnaire was administered to the parents of case and control infants by trained interviewers who were blinded to the origin of the chromosome error in each case. Questions covered demographic factors, pregnancy, medical and family history, and environmental exposures including maternal cigarette smoking and $\mathrm{OC}$ use. The interviews were conducted in person with each parent separately. For maternal cigarette smoking, women were asked if they had smoked 100 or more cigarettes in their lifetime. Those who said yes were asked how old they were when they started smoking, whether they had smoked regularly since the onset of smoking, the average number of cigarettes they smoked per day, and whether they were still smoking at the time of conception of the index case. Women who had never smoked a total of 100 cigarettes were considered nonsmokers (category: "never smoked"). Women who had smoked 100 or more cigarettes were classified as "ever smokers," and women who smoked at the time of conception were defined as "current smokers." The variable, pack-years, was calculated as the average number of cigarettes smoked per day times the number of years smoked, divided by 20 cigarettes per pack.
For maternal OC use, women who used OC any time before 2 months before the date of conception of the index case were considered "prior OC users." Those who used OC any time during the period from 2 months before through 2 months after the conception of the index case were defined as "current OC users." All "current OC users," except for one case mother, also had a history of prior OC use.

\section{Statistical analysis}

We examined the ORs for the population-based case-control data grouped in four ways: (1) all cases (i.e., PMI, PMI, MMI, "MMII", and unknown); (2) all maternally derived cases (including MMI, "MMII," and maternal stage unknown [MM] cases); (3) MMI cases only; and (4) "MMII" cases only. In estimating ORs, we used all control subjects for each case subgroup.

We used logistic regression in SAS ${ }^{21}$ to calculate adjusted ORs for the 4 groups of cases. The ORs were adjusted for maternal age (as a continuous variable), educational attainment of the mothers (less than high school and high school or above), and racial group (white, black, and others). When the estimated OR was significant and the number of cases was less than 5 in any cell of the 2-by-2 table, we recalculated the adjusted ORs by an exact procedure using LogXact software (CyTEL Software Corp., Cambridge, MA). ${ }^{22}$ We found no statistically significant difference between the estimates obtained by using SAS and LogXact for these adjusted ORs. Therefore, we have reported only the ORs from the SAS logistic procedure.

We examined the interaction effects of maternal smoking and OC use within \pm 2 months of conception in the following way. To maximize the sample sizes in each cell, we collapsed each exposure into two categories based on whether the exposures were present within \pm 2 months of conception of the index case. Thus, for smoking, "never smoked" and "ever smoked" categories were collapsed into "nonsmokers." Similarly, for OC use, the "never used" and "ever used" categories were collapsed into

Table 2

Parent of origin and timing of the nondisjunction error in nonmosaic DS

\begin{tabular}{lcccl}
\hline & Liveborn & TAB" $^{\prime}$ & Total & Proportion \\
\hline Paternal & & & & \\
Meiosis I (PMI) & 10 & 1 & 11 & PMI/(PMI + PMII) $=11 / 19=57.9 \%$ \\
Meiosis II (PMII) & 7 & 1 & 8 & PMII(PMI + PMII) $=8 / 19=42.1 \%$ \\
Stage unknown & 1 & 1 & 2 & \\
Subtotal & 18 & 3 & 21 & Pat/All meiotics $=21 / 237=8.9 \%$ \\
Maternal & 151 & 18 & 169 & MMI/(MMI + "MMII") $=169 / 206=82.0 \%$ \\
Meiosis I (MMI) & 35 & 2 & 37 & "MMII"/(MMI + "MMII") $=37 / 206=18.0 \%$ \\
"Meiosis II" ("MMII") & 9 & 1 & 10 & \\
Stage unknown & 195 & 21 & 216 & Mat/All meiotics $=216 / 237=91.1 \%$ \\
Subtotal & 11 & 1 & 12 & Mitotics/All known $=12 / 249=4.8 \%$ \\
Mitotics & 25 & 11 & 36 & Unknown/All $=36 / 285=12.6 \%$ \\
Unknown & 249 & 36 & 285 & \\
Total cases & & & & \\
\hline
\end{tabular}

"TAB, therapeutic abortion.

MMI and "MMII" indicate origin and timing of nondisjunction (see text). 
"non-OC user." Thus the interaction table included four categories for case and control subjects: (1) nonsmoker, non-OC user; (2) nonsmoker, OC user; (3) smoker, non-OC user; and (4) smoker, OC user.

We calculated OR estimates for all women as a group as well as for women $<35$ years of age and $\geq 35$ years of age separately. This division is based on studies which have demonstrated that the rise in DS risk is greatest for women $\geq 35 .^{23-25}$ We also calculated the ORs for maternal smoking and OC use in women $<30$ and $\geq 30$ years of age and found trends similar to those that we obtained using 35 years as a cutoff point (results not shown).

\section{RESULTS}

Of the 237 meiotic cases for which parental origin could be assigned, $91.1 \%$ were maternally derived and $8.9 \%$ were paternally derived ( Table 2). Among paternal cases, $57.9 \%$ of the errors occurred during PMI, whereas among maternal cases, $82.0 \%$ of errors occurred during MMI. Because there were too few paternally derived cases, we confined our current analysis to maternal cases (MMI and "MMII"). All analyses were done both excluding and including DS cases which were ter- minated prenatally. Because we found no differences in the results, we combined pregnancy terminations and livebirths in the present report.

Table 3 shows selected characteristics of the case and control mothers by meiotic origin of the chromosome error. As expected, the mean maternal age of cases ( 31.5 years) was significantly higher than that of controls $(27.5 ; P<0.05)$. The mean parity (2.5) among mothers of "MMII" cases was significantly higher than the parity of mothers of controls and other subgroups (2.0; $P<0.05)$. This is probably related to the fact that the former are older. The proportion of whites was significantly higher among all cases $(59.3 \%)$ than among controls $(49.2 \%, P<0.05)$. The proportion of current smokers $(21.6 \%)$ was significantly higher among mothers of "MMII" cases when compared with mothers of MMI cases $(11.8 \% ; P<0.05)$. We did not find any other significant differences between the mothers of other case subgroups or control mothers with respect to the selected characteristics (Table 3 ).

When we analyzed all Down syndrome cases together, we found no evidence of an association between maternal cigarette smoking and the risk for DS (Table 4). When the cases

Table 3

Selected characteristics of case and control mothers by parent of origin and timimg of nondisjunction of chromosome 21

\begin{tabular}{|c|c|c|c|c|c|c|c|c|c|c|}
\hline \multirow{3}{*}{$\frac{\text { Characteristic }}{\text { Mean maternal age (SD) }}$} & \multicolumn{2}{|c|}{ All Meiotic cases ${ }^{i}$} & \multicolumn{2}{|c|}{ All Maternal } & \multicolumn{2}{|c|}{ MMI } & \multicolumn{2}{|c|}{ "MMII" } & \multicolumn{2}{|c|}{ Controls } \\
\hline & $n$ & & $n$ & & $n$ & & $n$ & & $n$ & \\
\hline & 273 & $31.5(6.9)$ & 216 & $31.7(6.8)$ & 169 & $31.8(6.6)$ & 37 & $32.4(7.4)$ & 329 & $27.5(6.2)$ \\
\hline Mean parity (SD) & 273 & $2.1(1.4)$ & 216 & $2.1(1.4)$ & 169 & $2.0(1.2)$ & 37 & $2.5(2.0)$ & 329 & $2.0(1.3)$ \\
\hline Mean $n$ of miscarriages (SD) & 273 & $0.38(0.7)$ & 216 & $0.32(0.7)$ & 169 & $0.33(0.7)$ & 37 & $0.30(0.7)$ & 329 & $0.33(0.7)$ \\
\hline \multicolumn{11}{|l|}{ Education } \\
\hline Less than high school & 35 & $12.8 \%$ & 24 & $11.1 \%$ & 19 & $11.2 \%$ & 4 & $10.8 \%$ & 63 & $19.2 \%$ \\
\hline High school+ & 238 & $87.2 \%$ & 192 & $88.9 \%$ & 150 & $88.8 \%$ & 33 & $89.2 \%$ & 266 & $80.8 \%$ \\
\hline \multicolumn{11}{|l|}{ Race } \\
\hline White & 162 & $59.3 \%$ & 130 & $60.2 \%$ & 100 & $59.2 \%$ & 24 & $64.9 \%$ & 162 & $49.2 \%$ \\
\hline Black & 89 & $32.6 \%$ & 69 & $31.9 \%$ & 56 & $33.1 \%$ & 10 & $27.0 \%$ & 142 & $43.2 \%$ \\
\hline Other & 22 & $8.1 \%$ & 17 & $7.9 \%$ & 13 & $7.7 \%$ & 3 & $8.1 \%$ & 25 & $7.6 \%$ \\
\hline \multicolumn{11}{|l|}{ Maternal smoking } \\
\hline Never smoked & 187 & $68.5 \%$ & 152 & $70.4 \%$ & 120 & $71.0 \%$ & 24 & $64.9 \%$ & 225 & $71.0 \%$ \\
\hline Ever smoked & 86 & $31.5 \%$ & 64 & $29.6 \%$ & 49 & $29.0 \%$ & 13 & $35.1 \%$ & 95 & $28.9 \%$ \\
\hline Current smokera & 42 & $15.4 \%$ & 29 & $13.4 \%$ & 20 & $11.8 \%$ & 8 & $21.6 \%$ & 52 & $15.8 \%$ \\
\hline \multicolumn{11}{|l|}{ Total pack-years } \\
\hline$<5$ & 44 & $16.1 \%$ & 32 & $14.8 \%$ & 26 & $15.4 \%$ & 6 & $16.2 \%$ & 54 & $16.4 \%$ \\
\hline$\geq 5$ & 42 & $15.4 \%$ & 32 & $14.8 \%$ & 23 & $13.6 \%$ & 7 & $18.9 \%$ & 40 & $12.2 \%$ \\
\hline \multicolumn{11}{|l|}{ Maternal OC use } \\
\hline Never used OC & 48 & $17.6 \%$ & 39 & $18.1 \%$ & 25 & $17.1 \%$ & 6 & $14.3 \%$ & 56 & $17.0 \%$ \\
\hline Prior OC users & 225 & $82.4 \%$ & 177 & $81.9 \%$ & 121 & $82.9 \%$ & 36 & $85.7 \%$ & 273 & $83.0 \%$ \\
\hline Current $\mathrm{OC}$ user $^{b}$ & 24 & $8.8 \%$ & 18 & $8.3 \%$ & 12 & $8.2 \%$ & 5 & $11.9 \%$ & 49 & $15.0 \%$ \\
\hline
\end{tabular}

MMI and "MMII" indicate origin and timing of nondisjunction (see text). OC, oral contraceptive.

"Current smoker includes mothers who smoked any time from 2 months before to 2 months after conception of the index case. ${ }^{6}$ Current OC user includes mothers who used OC any time from 2 months before to 2 months after conception of the index case. All "current OC users," except
one case mother, also had a history of prior OC use sometime during their reproductive years.

The category "All meiotic cases" includes the cases of unknown origin. A small proportion of these unknown cases may be mitotic in origin. 
Table 4

Association of maternal smoking with nondisjunction of chromosome 21 by origin of error and maternal age: Adjusted OR and $95 \% \mathrm{CI}$

\begin{tabular}{|c|c|c|c|c|c|c|c|c|c|}
\hline \multirow[b]{2}{*}{ Characteristic } & \multicolumn{3}{|c|}{ All ages } & \multicolumn{3}{|c|}{$<35$ years } & \multicolumn{3}{|c|}{$\geq 35$ years } \\
\hline & Case & Control & OR $(95 \% \mathrm{CI})$ & Case & Control & OR $(95 \% \mathrm{CI})$ & Case & Control & OR $(95 \% \mathrm{CI})$ \\
\hline All meiotic cases ${ }^{n}$ & 273 & 329 & & 175 & 292 & & 98 & 37 & \\
\hline Never smoked & 187 & 234 & 1.0 & 122 & 212 & 1.0 & 65 & 22 & 1.0 \\
\hline Ever smoked & 86 & 95 & $0.96(0.66-1.40)$ & 53 & 80 & $1.04(0.67-1.60)$ & 33 & 15 & $0.89(0.39-2.03)$ \\
\hline Current smoker ${ }^{b}$ & 42 & 52 & $0.96(0.60-1.54)$ & 30 & 47 & $1.03(0.61-1.73)$ & 12 & 5 & $1.15(0.31-4.22)$ \\
\hline \multicolumn{10}{|l|}{ Total pack-years } \\
\hline$<5$ & 44 & $54^{i}$ & $1.01(0.64-1.61)$ & 32 & 47 & $1.13(0.68-1.89)$ & 12 & 7 & $0.60(0.21-1.76)$ \\
\hline$\geq 5$ & 42 & 40 & $0.94(0.57-1.56)$ & 21 & 32 & $0.95(0.51-1.77)$ & 21 & 8 & $1.24(0.43-3.54)$ \\
\hline All maternal cases & 216 & 329 & & 137 & 292 & & 79 & 37 & \\
\hline Never smoked & 152 & 234 & 1.0 & 96 & 212 & 1.0 & 56 & 22 & 1.0 \\
\hline Ever smoked & 64 & 95 & $0.89(0.60-1.33)$ & 41 & 80 & $0.98(0.62-1.57)$ & 23 & 15 & $0.71(0.30-1.67)$ \\
\hline Current smoker & 29 & 52 & $0.84(0.50-1.42)$ & 21 & 47 & $0.90(0.50-1.62)$ & 8 & 5 & $0.82(0.20-3.30)$ \\
\hline \multicolumn{10}{|l|}{ Total pack-years } \\
\hline$<5$ & 32 & $54^{i}$ & $0.91(0.55-1.51)$ & 24 & 47 & $1.06(0.60-1.85)$ & 8 & 7 & $0.44(0.14-1.40)$ \\
\hline$\geq 5$ & 32 & 40 & $0.90(0.53-1.55)$ & 17 & 32 & $0.93(0.48-1.80)$ & 15 & 8 & $1.03(0.35-3.09)$ \\
\hline MMI cases & 169 & 329 & & 107 & 292 & & 62 & 37 & \\
\hline Never smoked & 120 & 234 & 1.0 & 78 & 212 & 1.0 & 42 & 22 & 1.0 \\
\hline Ever smoked & 49 & 95 & $0.85(0.55-1.32)$ & 29 & 80 & $0.86(0.51-1.44)$ & 20 & 15 & $0.78(0.32-1.89)$ \\
\hline Current smoker & 20 & 52 & $0.72(0.40-1.29)$ & 13 & 47 & $0.69(0.35-1.37)$ & 7 & 5 & $0.81(0.20-3.29)$ \\
\hline \multicolumn{10}{|l|}{ Total pack-years } \\
\hline$<5$ & 26 & $54^{c}$ & $0.92(0.54-1.59)$ & 19 & 47 & $1.03(0.56-1.89)$ & 7 & 7 & $0.47(0.14-1.60)$ \\
\hline$\geq 5$ & 23 & 40 & $0.80(0.44-1.45)$ & 10 & 32 & $0.67(0.31-1.47)$ & 13 & 8 & $1.13(0.37-3.40)$ \\
\hline "MMII" cases & 37 & 329 & & 21 & 292 & & 16 & 37 & \\
\hline Never smoked & 24 & 234 & 1.0 & 11 & 212 & 1.0 & 13 & 22 & 1.0 \\
\hline Ever smoked & 13 & 95 & $1.14(0.54-2.40)$ & 10 & 80 & $2.43(0.89-6.63)$ & 3 & 15 & $0.37(0.07-1.87)$ \\
\hline Current smoker & 8 & 52 & $1.55(0.64-3.76)$ & 7 & 47 & $2.98(1.01-8.87)$ & 1 & 5 & $0.65(0.06-7.48)$ \\
\hline \multicolumn{10}{|l|}{ Total pack-years } \\
\hline$<5$ & 6 & $54^{c}$ & $1.04(0.39-2.75)$ & 5 & 47 & $2.23(0.68-7.32)$ & 1 & 7 & $0.24(0.02-2.56)$ \\
\hline$\geq 5$ & 7 & 40 & $1.28(0.49-3.30)$ & 5 & 32 & $2.80(0.82-9.59)$ & 2 & 8 & $0.50(0.08-3.33)$ \\
\hline
\end{tabular}

MMI and "MMII" indicate origin and timing of nondisjunction (see text). Odds ratios (OR) were adjusted for maternal age (as a continuous variable), educational attainment, and racial group. $\mathrm{CI}$, confidence intervals.

"The category "All meiotic cases" includes the cases of unknown origin. A small proportion of these unknown cases may be mitotic in origin.

${ }^{b}$ Current smoker includes mothers who smoked any time between 2 months before and 2 months after conception of the index case.

'One control was excluded in calculating total pack-years of smoking because information on number of cigarettes smoked was not available.

were analyzed separately by the timing of the error, we found suggestive evidence of a differential effect of smoking between MMI and "MMII" cases. There was a decreased risk for DS among MMI cases and an increased risk for "MMII" cases although the ORs were not significant (MMI: OR $=0.72,95 \%$ $\mathrm{CI}=0.40-1.29$; "MMII": $\mathrm{OR}=1.55,95 \% \mathrm{CI}=0.64-3.76$ ). This differential effect was more pronounced among women younger than 35 years and reached significance for "MMII" cases (MMI: $\mathrm{OR}=0.69,95 \% \mathrm{CI}=0.35-1.37$; “MMII": $\mathrm{OR}=2.98,95 \% \mathrm{CI}$ $=1.01-8.87 ; \mathrm{P}=0.0495)$. Also, among younger women, there was suggestive evidence of a dose-response relationship; that is, the risk for an "MMII" error among younger women $(<35$ years of age) increased from $2.23(95 \% \mathrm{CI}=0.68-7.32)$ to 2.80 $(95 \% \mathrm{CI}=0.82-9.59)$ as pack-years increased.

We then examined the effect of smoking and OC use (Table $5)$. For those women younger than age 35 who smoked and used OC around the time of conception of the index case, the OR for DS was $7.62(95 \% \mathrm{CI}=1.63-35.6, P=0.0098)$ for "MMII" cases (Table 5). There were no women $\geq 35$ who smoked and used OC. We found no interaction effect of maternal cigarette smoking and $\mathrm{OC}$ use when all maternal cases were analyzed together, nor was an interaction seen among MMI 
Table 5

Association of maternal smoking and oral contraceptive use around the time of conception with nondisjunction of chromosome 21 (by origin of the error and maternal age). Adjusted $\mathrm{OR}$ and $95 \% \mathrm{CI}$

\begin{tabular}{|c|c|c|c|c|c|c|c|c|c|c|}
\hline \multirow[b]{2}{*}{ Smoking } & \multirow[b]{2}{*}{ OC use } & \multicolumn{3}{|c|}{ All ages } & \multicolumn{3}{|c|}{$<35$ Years } & \multicolumn{3}{|c|}{$\geq 35$ Years } \\
\hline & & Case & Control & OR $(95 \% \mathrm{CI})$ & Case & Control & OR $(95 \% \mathrm{CI})$ & Case & Control & OR $(95 \% \mathrm{CI})$ \\
\hline \multicolumn{11}{|c|}{ All maternal } \\
\hline$-a$ & - & 174 & 235 & 1.0 & 105 & 203 & 1.0 & 69 & 32 & 1.0 \\
\hline- & + & 13 & 42 & $0.59(0.30-1.16)$ & 11 & 42 & $0.55(0.27-1.13)$ & 2 & 0 & - \\
\hline+ & - & 24 & 45 & $0.73(0.42-1.28)$ & 16 & 40 & $0.73(0.38-1.38)$ & 8 & 5 & $0.95(0.24-3.74)$ \\
\hline+ & + & 5 & 7 & $1.36(0.40-4.61)$ & 5 & 7 & $1.41(0.43-4.36)$ & 0 & 0 & - \\
\hline \multicolumn{11}{|l|}{ MMI } \\
\hline- & - & 139 & 235 & 1.0 & 85 & 203 & 1.0 & 54 & 32 & 1.0 \\
\hline- & + & 10 & 42 & $0.58(0.27-1.21)$ & 9 & 42 & $0.56(0.26-1.21)$ & 1 & 0 & - \\
\hline+ & - & 18 & 45 & $0.67(0.37-1.25)$ & 11 & 40 & $0.62(0.30-1.27)$ & 7 & 5 & $0.89(0.23-3.54)$ \\
\hline+ & + & 2 & 7 & $0.70(0.14-3.61)$ & 2 & 7 & $0.76(0.15-3.76)$ & 0 & 0 & - \\
\hline \multicolumn{11}{|l|}{ "MMII" } \\
\hline- & - & 27 & 235 & 1.0 & 13 & 203 & 1.0 & 14 & 32 & 1.0 \\
\hline- & + & 2 & 42 & $0.66(0.15-3.00)$ & 1 & 42 & $0.38(0.05-3.01)$ & 1 & 0 & - \\
\hline+ & - & 5 & 45 & $1.06(0.38-3.01)$ & 4 & 40 & $1.54(0.45-5.27)$ & 1 & 5 & $1.03(0.09-11.7)$ \\
\hline+ & + & 3 & 7 & $5.82(1.28-26.4)$ & 3 & 7 & $7.62(1.63-35.6)$ & 0 & 0 & - \\
\hline
\end{tabular}

MMI and "MMII" indicate origin and timing of nondisjunction (see text). Odds ratios (OR) were adjusted for maternal age (as a continuous variable), educational attainment, and racial group.

Smoking and oral contraceptive use were two dichotomous variables: current smokers (smoking at \pm 2 months of conception of index case) vs nonsmokers (see footnote $"$ for explanation), and OC user ( \pm 2 months of conception of index case) vs non-OC users. Plus sign $(+)$ indicates exposure, and minus sign $(-)$ indicates no exposure.

"The category "non-smokers" was formed by collapsing "never-smoked" and "ever-smoked". This grouping was possible because the ORs for those who had smoked in the past were not statistically different from unity (Table 4).

cases. After controlling for smoking, we found no significant association between OC use alone and the risk for DS (Table 5).

One source of potential bias in retrospective case-control studies of environmental exposures is the differential recall between case and control subjects. ${ }^{26}$ To examine the potential recall bias in the study of birth defects, Khoury et al..$^{27}$ proposed using "affected controls," that is, subjects with birth defects other than the one under study. We used this approach in the present study of "MMII" cases by calculating ORs using all cases other than those with an "MMII" error as "affected controls." For maternal cigarette smoking, it is apparent that the OR estimations using "normal controls" (Table 4) and "affected controls" (Table 6) are essentially the same. Additionally, using "affected controls" to study the interaction between smoking and OC use results in OR estimations (Table 6) similar to those obtained using "normal controls" (Table 5). These results suggest that the observed association between cigarette smoking among OC users and the risk of having an "MMII" error is probably not the result of recall bias.

\section{DISCUSSION}

This is the first study to examine the role of environmental factors in trisomy 21 separately by the parent of origin and the timing of the nondisjunctional error. Because more than $90 \%$ of cases are the result of a maternal error and less than $10 \%$ are the result of paternal nondisjunction, our current sample size is only large enough to permit epidemiological studies of the maternal cases.

Our findings demonstrate an increased risk for DS in the offspring of women who smoke cigarettes around the time of conception. This effect is confined to "MMII" cases among women younger than 35 years of age. These results may be due to (1) small sample size, (2) recall bias, (3) differential intrauterine survival, or (4) a true effect of smoking on the meiotic process. Sample size will remain an issue, particularly with the less frequent "MMII" cases, until additional subjects can be enrolled to confirm these findings. However, in the present study, we used an exact procedure to validate the significant ORs estimated from the logistic analysis. We saw no effects of smoking or OC use among older mothers. We need to be cautious about drawing any conclusions about this group because the OR estimates are based on a relatively small number of control mothers compared with case mothers in the $\geq 35$ age group, that is $11 \%$ (37 of 329 ) of control mothers $\geq 35$ years old and $36 \%$ (98 of 273 ) of case mothers $\geq 35$ years old.

Recall bias is not a likely explanation for the differences in risks between MMI and "MMII" cases or for the significantly increased risk for "MMII" cases among younger mothers. First, neither the women who completed the questionnaire nor the interviewer was aware of the origin of the nondisjunctional 
error. Second, the estimated ORs based on normal controls and on "affected" controls (i.e., all other DS cases not due to "MMII" errors) were essentially the same.

Differential intrauterine survival of "MMII" cases among mothers who smoke around the time of conception also seems unlikely. If this were the correct explanation and MI fetuses were more sensitive to factors in the intrauterine environment, we would expect an increased ratio of MMI to "MMII" fetuses among spontaneous abortions compiared with livehirths; however, Zaragoza et al. $-"$ have shown that these ratios are similar. Although several studies have suggested that maternal smoking during pregnancy may increase the rate of spontineous ahortion of DS fetuses, ${ }^{4,6,7}$ none has grouped cases separately by the origin of the nondisjunctional error. Additional studies are needed.

The last possible explanation is that smoking with or without OC use has a true effect on the susceptibility of chromosome 21 to nondisjunction. There is little direct evidence of an effect of smoking on meiosis; however, it is well documented that maternal smoking delays conception, reduces fecundity, increases the risk for spontaneous abortions or early fetal death, and causes early menopause. ${ }^{29-33}$

With respect to the effect of OC use on the risk for DS, studies have produced conflicting results, but in general, no association has been established. Some have suggested that women who take oral contraceptives during the months just before conception or who have OC-breakthrough pregnancies have an increased risk of having a baby with DS. ${ }^{34-36}$ Others have found no evidence of an increased risk for DS among the offspring of mothers who use OC around the time of conception. ${ }^{37-41}$ A delay in conception after discontinuing $\mathrm{OC}$ use has been reported, but whether this is due to anovulation or an abnormality within the ovum is not known. ${ }^{42}$ Pregnancy loss before clinical recog. nition of the pregnancy may be incorrectly interpreted as an inability to conceive and, in this regard, it is well known that the major cause of early fetal loss is aneuploidy. ${ }^{43}$ However, our results provide no significant evidence that $\mathrm{OC}$ use alone is associated with an increased risk for DS.

The motivation to examine the combined effects of smoking and $\mathrm{OC}$ use on meiotic nondisjunction was based on the clear evidence of their interactive effects on other health conditions. For example, OC use by smokers increases their risk for vascular disease, including myocardial infarction, venous thrombosis, and stroke. ${ }^{18,19,44,45}$ We found a significantly increased risk for DS in the offspring of women who smoked and used OC around the time of conception and this risk was confined to "MMII" cases.

Our findings are consistent with one hypothesis that has been put forward to explain the effect of maternal age on the risk for nondisjunction. Gaulden ${ }^{46}$ proposed that hormonal imbalance might cause a less-than-optimal microvasculature to develop around the maturing oocytes. The resulting decrease in the size of the perifollicular bed would reduce the volume of blood flow through the area and lead to an oxygen deficit in the egg. In turn, the decreased intracellular $\mathrm{pH}$ of the oocyte would impair the spindle and result in chromosome displacement and nondisjunction. Recently, Van Blerkom et al. ${ }^{47}$ reported on the rela-

Table 6

Association of maternal smoking and OC use with "MMII" nondisjunction of chromosome 21 using affected controls. Adjusted OR and 95\% CI

\begin{tabular}{|c|c|c|c|c|c|c|c|c|c|c|}
\hline \multicolumn{3}{|c|}{ "MMII" } & \multicolumn{2}{|c|}{ All ages } & \multicolumn{3}{|c|}{$<35$ Years } & \multicolumn{3}{|c|}{$\geq 35$ Years } \\
\hline \multicolumn{2}{|c|}{ Maternal smoking } & Case & $\begin{array}{l}\text { Affected } \\
\text { control" }\end{array}$ & $\mathrm{OR}(95 \% \mathrm{CI})^{b}$ & Case & $\begin{array}{l}\text { Affected } \\
\text { control }^{\prime \prime}\end{array}$ & OR $(95 \% \mathrm{CI})^{h}$ & Case & $\begin{array}{l}\text { Affected } \\
\text { control }^{\circ}\end{array}$ & OR $(95 \% \mathrm{CI})^{b}$ \\
\hline \multicolumn{2}{|c|}{ Never smoked } & 24 & 169 & 1.0 & 11 & 115 & 1.0 & 13 & 54 & 1.0 \\
\hline \multicolumn{2}{|c|}{ Ever-smoked } & 13 & 79 & $1.12(0.53-2.36)$ & 10 & 47 & $2.33(0.86-6.29)$ & 3 & 32 & $0.28(0.06-1.31)$ \\
\hline \multicolumn{2}{|c|}{ Current smoker } & 8 & 38 & $1.52(0.62-3.76)$ & 7 & 26 & $3.20(1.05-9.76)$ & 1 & 12 & $-i$ \\
\hline \multicolumn{11}{|c|}{ Total pack-years } \\
\hline \multicolumn{2}{|l|}{$<5$} & 6 & 41 & $1.04(0.39-2.72)$ & 5 & 29 & $1.82(0.56-5.94)$ & 1 & 12 & $0.35(0.04-3.03)$ \\
\hline \multicolumn{2}{|l|}{$\geq 5$} & 7 & 38 & $1.21(0.54-3.18)$ & 5 & 18 & $3.37(0.94-12.1)$ & 2 & 20 & $0.23(0.03-1.86)$ \\
\hline \multicolumn{11}{|c|}{ Maternal smoking and OC. use } \\
\hline \multicolumn{11}{|c|}{ Smoking OC use } \\
\hline$-d$ & - & 27 & 193 & 1.0 & 13 & 120 & 1.0 & 14 & 73 & 1.0 \\
\hline- & + & 2 & 17 & $1.04(0.21-5.02)$ & 1 & 16 & $0.45(0.05-3.97)$ & 1 & 1 & $6.90(0.32-146.8)$ \\
\hline+ & - & 5 & 34 & $1.09(0.38-3.12)$ & 4 & 22 & $1.96(0.55-6.93)$ & 1 & 12 & $-\mathfrak{c}$ \\
\hline+ & + & 3 & 4 & $6.18(1.24-30.8)$ & 3 & 4 & $6.86(1.32-35.7)$ & 0 & 0 & - \\
\hline
\end{tabular}

MMI and "MMII" indicate origin and timing of nondisjunction (see text).

Smoking and oral contraceptive use are two dichotomous variables: current smokers (smoking at \pm 2 months of conception of index case) vs nonsmokers (see footnote $d$ for explanation), and OC, use at \pm 2 months of conception of index case vs non-OC users. Plus sign $(+)$ indicates exposure, and minus sign $(-)$ indicates nonexposure.

"Affected controls includes all Down syndrome cases except MMII cases (including 12 cases of mitotic origin).

"Odds ratios were adjusted for maternal age (as a continuous variable), educational attainment, and racial group.

'The estimates of odds ratios were unstable because of the small numbers.

"The category "non-smokers" was formed by collapsing "never-smoked" and "ever-smoked". This grouping was possible because the ORs for those who had smoked in the past were not statistically different from unity (Table 4). 
tionship between perifollicular blood flow traits and the behavior of chromosomes within the developing oocytes. They examined more than 1000 samples of follicular fluid from human oocytes and found that oocytes from severely hypoxic follicles had high frequencies of abnormalities in chromosome organization on the metaphase spindle, possibly leading to an increased susceptibility to nondisjunction. Furthermore, they found that follicle-specific blood flow traits were associated with the intrafollicular oxygen levels. Because OC use among smokers carries an increased risk for thromboembolism, it is possible that the microvasculature of the ovary could be compromised. Blockage of small vessels by thromboembolic events would impair the delivery of oxygen to the follicles and their developing oocytes. We can conjecture that this in turn might affect the spindle or some other component of the meiotic mechanism such as the chromosome-stabilizing chiasmata.

The fact that maternal smoking ( \pm OC) increased the risk for an "MMII" error and not for an MMI error may shed light on the processes leading to nondisjunction. Perhaps the eggs destined to be the MMI cases are, because of their absent or misplaced chiasmata, inherently more susceptible to nondisjunction as a woman gets older, and the additional effect of environmental factors is largely irrelevant. On the other hand, the eggs destined to undergo an "MMII" error may have a recombination pattern that dictates a higher requirement for a second hit (age and/or environmental factors) before an actual error occurs in chromosome segregation. Alternatively, the finding that the effects of smoking and OC are limited to "MMII" cases may indicate that the mechanisms leading to "MMII" nondisjunction are different from those leading to an MMI error. For example, one likely mechanism for MMI cases associated with no recombination or distal recombination may be related to improper spindle attachment to the kinetochores. Spindlekinetochore attachment may not be a strongly energy-dependent process. In contrast, the mechanism leading to errors associated with pericentromeric recombination (i.e., "MMII" errors) may be highly energy-dependent. It may take a stronger constant spindle force to ensure correct segregation of homologs with a recombinant event very close to the centromere than it does with a more distal recombinant event. Our finding that the significantly increased ORs were limited to mothers younger than the age of 35 may indicate that the true effect of environmental exposures may only be evident among younger mothers. That is, in older women, the effect of time alone may be sufficient to disrupt meiotic events, and maternal age may obscure the effect of any added environmental exposures.

Research on additional cases is needed to confirm and expand upon these findings. Further molecular work on these and subsequent DS cases will permit us to categorize the cases according to the number and location of recombination events and to re-examine the impact of smoking and $\mathrm{OC}$ use on these groups. In addition, work is in progress to examine smoking and OC use in a different DS population. A parallel, population-based study has been conducted in Denmark using the same questionnaires and the same laboratory methodology. A preliminary analysis of the Danish data has not confirmed the findings in the present study (unpublished data, 1998). However, adequate controls were not available for that population, which limits the conclusions drawn from those data.

The main purpose of this ongoing research is to understand the nature of nondisjunction. That is, although studies such as this one may indicate that a particular environmental factor such as smoking is a risk factor in its own right, the more important outcome of these studies may be their contribution toward understanding the basic process of chromosome nondisjunction. This knowledge should have significance for all cases regardless of the specific environmental factors that might be involved in a few.

\section{Acknowledgments}

We are indebted to the families who participated in this study. We thank Drs. Cynthia Moore, W. Dana Flanders, Paula Yoon, Richard Olney, Lorenzo D. Botto, Roumiana Boneva, and James Buehler for their helpful comments on early drafts of the manuscript. We thank Emory Clinical Research Center for preparing the lymphoblastoid cell lines for the present study.

This work was supported by NIH contract NOl HD92907 and NIH grant PO1 HD32111.

\section{References}

1. Hook EB, Hamerton IL. The frequency of chromosome abnormalities detected in consecutive newborn studies, differences between studies, results by sex and by severity of phenotypic involvement. In: Hook EB, Porter IH, editors. Population cytogenetics: Studies in humans. New York: Academic Press, 1997;63-69.

2. Hassold TJ, lacobs PA. Trisomy in man. Annu Rev Genet 1984;18:69-97.

3. Kline J, Stein Z. Environmental causes of aneuploidy: Why so elusive? In: Dellarco VL, Voyteck PE, Hollaender A, editors. Aneuploidy: Etiology and mechanisms. New York: Plenum Press, 1985

4. Kline J, Levin B, Shrout P, Stein Z, Susser M, Warburton D. Maternal smoking and trisomy among spontaneously aborted conceptions. Am J Hum Genet 1983:35:421-431.

5. Kline I, Levin B, Stein Z, Warburton D, Hindin R. Cigarette smoking and trisomy 21 at amniocentesis. Genet Epidemiol 1993;10:35-42.

6. Hook EB, Cross PK. Cigarette smoking and Down syndrome. Am J Hum Genet 1985;37:1216-1224.

7. Hook EB, Cross PK. Maternal cigarette smoking, Down syndrome in live births, and infant race. Am J Hum Genet 1988;42:482-489.

8. Shiono PH, Klebanoff MA, Berendes HW. Congenital malformations and maternal smoking during pregnancy. Teratology 1986;34:65-71.

9. Christianson RE, Torfs CP. Maternal smoking and Down syndrome. Am J Hum Genet $1988 ; 43: 545-546$.

10. Van den Eeden SK, Karagas MR, Daling JR, Vaughan TL. A case-control study of maternal smoking and congenital malformations. Paediat Perinat Epidemiol 1990;4:147-155.

11. Cuckle HS, Alberman E, Wald NJ, Royston P, Knight G. Maternal smoking habits and Down's syndrome. Prenat Diagn 1990;10:561-567.

12. Källén K. Down's syndrome and maternal smoking in early pregnancy. Genet Efidemiol 1997; 14:77-84.

13. Antonarakis SE, Petersen MB, McInnis MG, Adelsberger PA, Schinzel AA, Binkert F Pangalos C, Raoul O, Slaugenhaupt SA, Hafez M, Cohen MM, Roulson D, Schwartz S, Mikkelsen M. Tranebjaerg L, Greenberg F, Hoar DI, Rudd NL, Warren AC, Metaxotou C, Barsocas C. Chakravarti A. The meiotic stage of nondisjunction in trisomy 21: Determination by using DNA polymorphisms. Am J Hum Genet 1992;50:544-50.

14. Petersen $\mathrm{MB}$. Comparative study of microsatellite and cytogenetic markers for detecting the origin of the nondisjoined chromosome 21 in Down syndrome. Am J Hum Genet 1992;51:516-525.

15. Sherman SL, Peterson MB, Freeman SB, Hersey J, Pettay D, Taft L, Frantzsen M Mikkelsen M, Hassold TJ. Non-disjunction of chromosome 21 in maternal meiosis 1: Evidence for a maternal age-dependent mechanism involving reduced recombination. Hum Mol Genet 1994:3:1593-1535.

16. Lamb NE, Freeman SB, Savage-Austin A, Pettay D, Taft L, Hersey I, Gu Y, Shen J, Saker D, May KM, Avramopoulos D. Petersen MB, Hallberg A, Mikkelsen M, Hassold TI, Sherman SL. Susceptible chiasmate configurations of chromosome 21 predispose to non-disjunction in both maternal meiosis I and meiosis II. Nat Genet 1996;14:400-405.

17. Lamb NE, Feingold E, Savage A, Avramopoulos D, Freeman S, Gu Y, Hallberg A, Hersey J, Karadima G, Pettay D, Saker D, Shen J, Taft L, Mikkelsen M, Petersen MB, Hassold T, Sherman SL. Characterization of susceptible chiasma configurations that increase 
the risk for maternal nondisjunction of chromosome 21. Hum Mol Genet 1997;6:1391-1399.

18. Carr BR, Ory H. Estrogen and progestin components of oral contraceptives: Relationship to vascular disease. Contraception 1997;55:267-272.

19. WHO Collaborative Study. Acute myocardial infarction and combined oral contraceptives: Results of an international multicentre case-control study. Lance 1997;349:1202-1209.

20. Edmonds LD, Layde PM, James LM, Flynt JW, Erickson JD, Oakley GP Jr. Congenital malformations surveillance: Two American systems. Int / Epidemiol 1981;10:247-252.

21. SAS Institute Inc. SAS/STAT User Guide, Version 6, Fourth Edition. SAS Institute Inc. Cary, NC, 1990

22. CYTEL Software Corporation. LogXact for windows: User manual. CYTEL Software Corporation, Cambridge, MA, 1996.

23. Hook EB. Rates of chromosome abnormalities at different maternal ages. Obstet Gynecol 1981;58:282-285.

24. Hook EB. Maternal age, paternal age, and human chromosome abnormality: Nature, magnitude, etiology, and mechanisms of effects. In: Dellarco VL, Voytek PE, Hollaender A, editors. Aneuploidy: Etiology and mechanisms. New York, Plenum Press, 1985;117-129.

25. Yoon P, Freeman SB, Sherman SL, Taft L, Gu YC, Pettay D, Flanders WD, Khoury MJ, Hassold T). Advanced maternal age and the risk of Down syndrome characterized by the meiotic stage of the chromosomal error: A population-based study. Am J Hum Genet 1996;58:628-633.

26. Rothman KJ, Greenland S. Modern epidemiology. Philadelphia: Lippincott-Raven Publishers, 1998.

27. Khoury, HJ, James LM, Erickson JD. On the use of affected controls to address recall bias in case-control studies of birth defects. Teratology 1994;49:273-281.

28. Zaragoza MV, Jacobs PA, James RS, Rogan P, Sherman S, Hassold T. Nondisjunction of human acrocentric chromosomes: Studies of 432 trisomic fetuses and liveborns. Hum Genet 1994;94:411-417.

29. Baird DD, Wilcox AJ. Cigarette smoking associated with delayed conception. JAMA 1985;253:2979-2983.

30. Landesman-Dwyer S, Emanuel 1. Smoking during pregnancy. Teratology 1979;19:119-125.

31. Surgeon General. The health consequences of smoking for women. A report of the Surgeon General. Washington, DC: Government Printing Office, 1985;189-249.
32. Werler MM, Pober BR, Holmes LB. Smoking and pregnancy. Teratology 1985;32:473-481.

33. Baron JA, La Vecchio C, Levi $F$. The antiestrogenic effect of cigarette smoking in women. Am J Obstet Gynecol 1990;162:502-514.

34. Lejeune J, Prieur M. Oral contraceptives and trisomy 21. A retrospective study of 730 cases. Ann Genet 1979;22:61-66.

35. Harlap S, Eldor J. Births following oral contraceptive failure. Obstet Gynecol 1980;55:447-452.

36. Mikkelsen M. Epidemiology of trisomy 21: Population, peri- and antenatal data. Hum Genet 1981;2 Suppl:211-226.

37. Harlap S, Shiono PH, Ramcharan S, Golbus M, Bachman R, Mann J, Lewis JP. Chromosomal abnormalities in the Kaiser-Permanente birth defects study, with special reference to contraceptive use around the time of conception. Teratology 1985;31:381-387.

38. Janerich DT, Flink EM, Keogh MD. Down's syndrome and oral contraceptive usage. Br J Obstet Gynaecol 1976;83:617-620.

39. Ericson A, Källén B, Lindsten J. Lack of correlation between contraceptive pills and Down's syndrome. Acta Obstet Gynecol Scand 1983;62:511-514.

40. Lammer EJ, Cordero IF. Exogenous sex hormone exposure and the risk for major malformations. JAMA 1986;255:3128-3132.

41. Källén B. Maternal use of oral contraceptives and Down syndrome. Contraception 1989;39:503-506.

42. Bracken MB, Hellenbrand KG, Holford TR. Conception delay after oral contraceptive use: The effect of estrogen dose. Fertil Steril 1990;53:21-27.

43. Hassold T, Hunt PA, Sherman SL. Trisomy in humans: Incidence, origin, and etiology. Curr Opin Genet Dev 1993;3:398-403.

44. Burkman RT. The estrogen component of OCs: Cardiovascular benefits and risks. Int J Fertil Womens Med 1997;1 Suppl:145-157.

45. Lewis MA, Heinemann LA, Spitzer WO, MacRae KD, Bruppacher R. The use of oral contraceptives and the occurrence of acute myocardial infarction in young women. Results from the Transnational Study on Oral Contraceptives and the Health of Young Women. Contraception 1997;56:129-140.

46. Gaulden ME. Maternal age effect: The enigma of Down syndrome and other trisomic conditions. Mutat Res 1992;296:69-88.

47. Van Blerkom J, Antczak M, Schrader R. The developmental potential of the human oocyte is related to the dissolved oxygen content of follicular fluid: Association with vascular endothelial growth factor levels and perifollicular blood flow characteristics. Hum Reprod 1997;12:1047-1055. 